\title{
Mobilizando os direitos humanos: a denúncia pública do Comitê Popular da Copa de Porto Alegre e suas implicações
}

Gabrielle Oliveira de Araujo*

\section{Resumo}

Neste artigo proponho o diálogo entre a sociologia da ação coletiva e o campo de discussão sobre direitos humanos para analisar a relação entre direito e mobilização coletiva numa conjuntura de conflito político em torno do direito à cidade e à moradia digna. Os dados que dão sustentação à análise resultam de uma pesquisa etnográfica em andamento sobre as ações coletivas contestatórias do Comitê Popular da Copa de Porto Alegre às intervenções do poder público municipal para as obras da Copa do mundo FIFA na cidade. 0 foco é dado para a dimensão estratégica e simbólica do direito e dos tribunais no curso da mobilização de grupos políticos e movimentos sociais. Tal análise visa a uma reflexão sobre como e por que as organizações sociais mobilizam as normas jurídicas e tribunais como recurso estratégico de mobilização contestatória com o objetivo de intervir no curso das políticas públicas e os efeitos para os diferentes agentes implicados nessa questão.

\section{Palavras-chave}

Mobilização coletiva. Direitos humanos. Comitê Popular da Copa de Porto Alegre.

\section{Abstract}

In this article I propose dialogue between sociology of collective action and the scope of the discussion on human rights to analyze the relationship between law and collective mobilization in a context of political conflict over the right to the city and dignified housing. The data that support the analysis result of an ongoing ethnographic research on collective action contesting the People's Committee of Porto Alegre Cup interventions of municipal government works for the FIFA World Cup in the city. The focus is given to the strategic and symbolic dimension of law and courts in the course of mobilization of political groups and

* Doutoranda do Programa de Pós-Graduação em Sociologia da Universidade Federal do Rio Grande do Sul; integrante do Grupo de Pesquisa Associativismo, Contestação e Engajamento (GPACE). Email: gabie.araujo@gmail.com. 
social movements. This analysis aims at reflecting on how and why social organizations mobilize the legal framework and courts as a strategic resource mobilization contestatory in order to intervene in the course of public policy and the effects for the different actors involved in this matter.

\section{Keywords}

Collective mobilization. Human rights. World Cup People's Committee of Porto Alegre.

\section{Introdução}

Manhã de março de 2013. Desço do ônibus em frente ao escritório do Departamento Municipal de Habitação, instalado pela prefeitura na Vila Cruzeiro, zona sul de Porto Alegre, para tratar da política de remoção de 1500 famílias atingidas pela duplicação de uma avenida, a qual comporá o acesso ao Estádio Beira-Rio nos jogos da Copa do Mundo FIFA 2014. Caminho pela avenida em obras, num cenário de demolição urbana. Eu me encontro, no posto de saúde do bairro, com dois militantes do Comitê Popular da Copa de Porto Alegre. Nosso destino era a casa de Dona Joana ${ }^{1}$. Quando chegamos lá, nos deparamos com um terreno cheio de entulhos e tijolos. Ao fundo, uma portinha indicava que ali ainda havia pessoas morando. Após nos apresentarmos e dizermos que estávamos ali com o intuito de gravar um vídeo de denúncia das violações de direitos da política de remoção no bairro, a nora de dona Joana disse que ela chegaria logo. Enquanto esperávamos a dona da casa, sua nora nos mostrou o terreno, apontando o esgoto a céuaberto e um canto cheio de ratos, os quais tinham comido a chupeta de seu filho e ela temia que o mordessem. Aquele cenário de destruição nos comovia e aos poucos descobrimos que aquela situação era resultado da demolição das casas dos filhos de Joana que já tinham saído do terreno. Era a prática da prefeitura para pressionar os que ficaram a sair $\log \sigma^{2}$, ela nos disse.

\footnotetext{
1 Utilizo neste caso um nome fictício visando evitar exposição demasiada e possíveis constrangimentos.

${ }^{2}$ Ao longo do texto me utilizo do recurso itálico para fazer referência às falas empíricas.
} 
Quando Joana chegou, ficamos sabendo que ela estava de mudança naquela semana, pois tinha optado pelo Bônus Moradia ${ }^{3}$. No relato que nos deu, Joana contou que morava na vila há 40 anos e que seu destino era Viamão, cidade vizinha, pois não conseguira encontrar casa em Porto Alegre. Ela também se queixou da demora da prefeitura para o atendimento no escritório e para a liberação dos papéis necessários para a mudança, chegando a mais de três meses de espera, o que estaria levando muita gente a perder as casas que encontravam à venda. A situação de violência me indignou e eu a questionei se não tinham acionado algum advogado, pois a situação que sua família vivia se configurava uma violação de direitos humanos. Ela me respondeu sem espanto que não, que haviam resolvido o problema acionando "o Mota". Perguntei: que Mota?, sem compreender do que ela falava. Ela me explicou então que era o apresentador de um programa popular chamado Balanço Geral e que com isso tinha conseguido pressionar a prefeitura a liberar o bônus e conseguir sua casa nova. Assim, ela se mudaria naquela semana mesmo.

O caso de Dona Joana ilustra a complexidade das lutas coletivas em torno dos direitos humanos, explicitando diferentes percepções existentes na apropriação da linguagem jurídica como forma de enquadrar e resolver situações sociais de conflito entre indivíduos e autoridades públicas. Esse fato chama a atenção para a necessidade de análises que levem em consideração as especificidades contextuais nas quais se dão as dinâmicas políticas e sociais contemporâneas, em especial nos países que têm suas políticas públicas estruturadas em longa trajetória de desigualdade social. É com intuito de contribuir com esse debate que este artigo visa problematizar a relação entre mobilizações coletivas e direitos humanos numa conjuntura específica de conflito urbano (à realização de grandes obras urbanas em função das obras da Copa FIFA 2014, na cidade de Porto Alegre).

Desse modo, analisa o uso da linguagem dos direitos humanos como recurso de interação política, em especial a partir da construção de uma denúncia pública (BOLTANSKI, 2000). O foco é dado para a dimensão estratégica e simbólica da linguagem dos direitos humanos a partir de uma

\footnotetext{
${ }^{3}$ São três as alternativas disponíveis para as famílias que compõem o público-alvo da política de remoção: indenização, reassentamento (via aluguel social) e o bônus moradia. Este último refere-se a um valor disponibilizado pela prefeitura para a compra de moradias escrituradas, sendo a prefeitura a mediadora do processo de compra. Mais adiante falarei com mais detalhes sobre a política de remoção.
} 
perspectiva etnográfica do conflito, a qual pressupõe uma compreensão das interações entre as partes envolvidas, a partir do contexto de experiência e da atribuição de sentidos ao conflito (CARDOSO DE OLIVEIRA, 2010) e do diálogo com autores do campo da sociologia e da antropologia que têm se dedicado a problematizar dimensões sobre a interface entre direito e lutas políticas (MACIEL, 2011; TISCORNIA, 2005; BORGES, 2008; COWAN; DEMBOUR; WILSON, 2001; RIBEIRO, 2004; SCHUSCH, 2009; FONSECA; CARDELLO, 1999). Mais especificamente, viso explorar como organizações, movimentos sociais e indivíduos têm se utilizado do discurso de direitos em busca de fins particulares e como eles tornam-se enredados nessa lógica.

Adiscussão estábaseada em uma pesquisa etnográfica quevenho realizando para a dissertação de mestrado, a qual tem como objeto de investigação as narrativas públicas e ações políticas do Comitê Popular da Copa de Porto Alegre (CPC/POA). Este se constitui uma rede política que tem atuado nos últimos quatro anos na produção de denúncias públicas dos denominados impactos urbanos e sociais decorrentes das obras de infraestrutura para a realização da Copa do Mundo FIFA 2014 (Copa 2014) na cidade. Ao longo desse período, a principal atividade em que essa rede esteve engajada foi na contestação da gestão municipal da política de remoções descrita no início deste artigo. Nesse cenário conflituoso, a rede em torno do CPC / POA tem lançado mão de um conjunto de estratégias de ações que têm acionado, particularmente, o campo dos direitos humanos como alternativa para a resolução do conflito em que estão envolvidos.

A partir desta introdução, o artigo está estruturado em cinco partes. Primeiramente, exponho o debate acadêmico que se formou no Brasil em torno do fenômeno dos megaeventos esportivos, situando a perspectiva deste artigo frente às pesquisas que vêm sendo realizadas sobre o tema. Em seguida, descrevo elementos empíricos da conjuntura da Copa FIFA 2014 e a emergência de mobilizações coletivas em torno dos direitos humanos, explicitando a problemática em que meus interlocutores estão inseridos e descrevendo as principais instituições e agentes envolvidos no processo mais geral. Na terceira parte, eu apresento a constituição do CPC/POA, relacionando as intervenções urbanas em Porto Alegre para a realização dos jogos da Copa 2014, para, em seguida, entrar na discussão sobre a construção da denúncia pública a partir da linguagem dos direitos humanos, problematizando dimensões presentes na interação com o campo jurídico e as implicações na prática para os diferentes sujeitos envolvidos. Por fim, as considerações finais. 


\section{País dos Megaeventos em Debate}

O Brasil vem sendo, na última década, palco de diferentes megaeventos esportivos ${ }^{4}$. Esse fato tem gerado um amplo debate político, social e acadêmico acerca dos significados e implicações dos discursos e ações governamentais, que defendem a realização destes megaeventos para as cidades brasileiras.

No Brasil, os pesquisadores dedicados a essa temática têm argumentado, de maneira consensual, que os governos brasileiros têm buscado atrair as competições esportivas como uma forma estratégica de promover um tipo de desenvolvimento pautado na implementação de grandes projetos de reestruturação e embelezamento urbano (MASCARENHAS; BORGES; MARQUES, 2011; RAEDER, 2011; FREIRE, 2011; MAGALHÃES, 2013; MARGUERITES, 2013; ÁLVARES; BESSA; BARBOSA, 2013; SANCHEZ; LIMA; HERDY, 2011). A realização desses megaeventos é apresentada pelas autoridades públicas brasileiras como um mecanismo promotor, meio ou até condicionantes para o exercício de políticas públicas, surgindo como uma verdadeira solução para o enfrentamento de problemas do país (GARCIA; LIMA; HERDY, 2011). Como contraponto a esse discurso centrado apenas nos aspectos positivos propiciados por tais competições, a literatura tem explorado os denominados impactos sociais e urbanos.

A problemática das remoções como um dos efeitos dos megaeventos tem sido um dos principais aspectos apontados pela literatura. Magalhães (2013) argumenta que o governo do Rio de Janeiro tem se utilizado do termo "legado" para reatualizar um repertório de remoções na cidade, justificando assim esse tipo de intervenção nas favelas cariocas. Diversos outros pesquisadores da temática urbana brasileira têm realizados estudos sobre essa questão em diferentes cidades brasileiras (CAPENA et al., 2011; FREIRE, 2011; SIQUEIRA; LAHORGUE, 2011; MARGUERITES, 2014).

Resultam dessas análises conclusões semelhantes: as grandes obras dos megaventos, em sua maioria de mobilidade urbana, estão sendo realizadas em regiões da cidade com grande interesse imobiliário, resultando na remoção de milhares de famílias. Apontam também para a instrumentalização das

\footnotetext{
${ }^{4}$ Em 2007, a cidade do Rio de Janeiro recebeu os Jogos Pan-Americanos; no ano de 2013, diversas cidades brasileiras recepcionaram a Copa das Confederações, a qual foi seguida pela realização da Copa do Mundo FIFA 2014, que teve início no mês de julho do presente ano; por fim, em 2016, o Rio de Janeiro sediará os Jogos Olímpicos.
} 
políticas habitacionais brasileira e a flexibilização de leis como meio de garantir o cronograma das obras, impondo um cenário atípico para a formulação das políticas públicas urbanas, no qual procedimentos normais de planejamento urbano são suspensos e os mecanismos de participação, ignorados (MARGUERITES, 2014). Essa conjuntura tem levado ao acirramento dos conflitos fundiários, isto é, à luta em torno do direito a ocupar uma determinada localidade da cidade (CAFRUNE, 2009). Famílias e organizações sociais têm se articulado na tentativa de barrar esse amplo processo de violação de direitos humanos.

Assim, a analítica em torno do país dos megaeventos traz as cidades e os conflitos territoriais para o centro do debate. Ao enfatizarem os impactos sociais e urbanos suscitados pelas obras públicas associadas às competições esportivas, os pesquisadores brasileiros têm reatualizado temas importantes do nosso país: projetos de desenvolvimento urbanos, políticas públicas de remoções populacionais, violação de direitos humanos e conflitos políticos. É justamente sobre tais questões que este artigo trata ao analisar a relação entre mobilizações coletivas e direitos humanos na conjuntura da preparação de Porto Alegre para a Copa 2014, a partir da construção da denúncia pública das remoções forçadas elaboradas pelo $\mathrm{CPC} / \mathrm{POA}$.

No entanto, tomo uma direção diferente e busco explorar a partir de dados etnográficos questões ausentes neste debate, isto é, problematizo o uso da linguagem jurídica na dinâmica dos conflitos políticos, visando desnaturalizar a ideia em torno da noção de direitos humanos como algo positivo e consensual da realidade social brasileira. Ressalto que o trabalho não visa se esgotar no tema dos megaeventos, mas a partir deste problematizar dimensões importantes ao campo de discussão contemporânea da ação coletiva e dos direitos humanos, contribuindo para a compreensão das especificidades brasileiras no momento presente.

Mas primeiramente irei expor os elementos característicos da conjuntura da Copa 2014 e a emergências de mobilizações sociais - objeto da minha pesquisa.

\section{A Copa 2014 e a Mobilização Coletiva dos Direitos Humanos}

No momento em que finalizo a escrita deste artigo, o Brasil já é o país da Copa 2014. Esse fato, quando do seu anúncio, em 2007, foi comemorado pelos governos brasileiros, que afirmaram que a realização do evento deixaria um relevante legado em infraestrutura, criação de emprego e renda e promoção 
do país em escala global. A comemoração se intensificou em 2009, com a escolha das doze cidades brasileiras que receberam os jogos do mundial ${ }^{5}$.

Os festejos "da Copa do Mundo é Nossa” foram seguidos pela instituição de um aparato institucional específico, em todos os níveis - municipal, estadual e federal -, visando à promoção de ações governamentais para o megaevento. Neste sentido, uma das primeiras ações governamentais foi a elaboração de um Programa de Aceleramento do Crescimento para a Copa (PAC Copa) ${ }^{6}$, o qual destina recursos públicos federais às cidades brasileiras sede dos jogos para obras estruturantes de infraestrutura e serviços urbanos, com a condição de que essas estejam concluídas antes do início da competição. Tais empreendimentos foram definidos e pactuados através da assinatura da Matriz de Responsabilidades ${ }^{7}$, em abril de 2010, entre União, Estados e municípios.

Todavia, a tentativa de constituição de um consenso pátrio dos benefícios da Copa 2014 para o país não tem se dado sem conflitos. As ações governamentais, resultantes da assinatura da Matriz de Responsabilidade, têm implicado numa importante intervenção no espaço físico da cidade, alterando seus usos pelos diversos grupos sociais (MAGALHÃES, 2013) e promovendo alterações significativas no ordenamento jurídico. Adquire centralidade nessa conjuntura a emergência da Articulação Nacional dos Comitês Populares da Copa e das Olimpíadas (ANCOP) ${ }^{8}$.

Essa rede que reúne acadêmicos, organizações sociais, militantes diversos e lideranças populares das doze cidades-sede do mundial foi formada em meados de 2010, num momento em que a Copa 2014 ainda não tinha se

\footnotetext{
${ }^{5}$ Manaus, Fortaleza, Natal, Recife, Salvador, Brasília, Cuiabá, Belo Horizonte, São Paulo, Curitiba, Rio de Janeiro e Porto Alegre.

${ }^{6}$ Mais informações disponíveis em: www.pac.gov.br/especial/10. Acesso em 10 de abril de 2014.

${ }^{7}$ Segundo o site do governo federal para a Copa 2014, a Matriz de Responsabilidade trata das áreas prioritárias de infraestrutura nas doze cidades-sede. O instrumento tem como objetivo definir as responsabilidades de cada ente signatário (União, Estados, Distrito Federal e municípios) para a execução de medidas conjuntas e projetos voltados para a realização do Mundial. Ao longo dos últimos anos, a Matriz de Responsabilidade passou por diversas alterações. Para mais informações: www.copa2014.gov.br/pt-br/brasilecopa/sobreacopa/matriz-responsabilidades. Acesso em 10 de abril de 2014.

${ }^{8}$ As informações utilizadas neste trabalho foram obtidas a partir do relatório de atividades da ANCOP, elaborado por seus membros no ano de 2013.
} 
transformado em um problema público ${ }^{9}$. A iniciativa de constituí-la resultou de discussões, ao longo de 2010, que tinham como eixo os impactos que o Brasil passaria a sofrer com a chegada dos megaeventos. Esse debate inicial centrava-se nas experiências internacionais e nacionais de cidades que foram sede de megaeventos esportivos e que tiveram como resultado a violação de múltiplos direitos fundamentais.

Dessas discussões surgiu a proposição de que fossem organizados Comitês Populares locais nas cidades-sede, demarcando, assim, o início da constituição da articulação nacional para a busca de soluções conjuntas aos impactos sociais, através da construção de ações coletivas visando monitorar e publicizar as violações de direitos e fortalecer as lutas sociais locais, principalmente relacionadas ao direito à cidade e à moradia digna de milhares de famílias em situação de vulnerabilidade.

Deste então, a ANCOP se transformou num importante interlocutor político entre governos e sociedade, particularmente dos denominados atingidos pelas obras da Copa, desenvolvendo diversas atividades que vão desde a realização de plenárias, formação de lideranças populares, produção de materiais informativos, atos públicos e elaboração de denúncias de violação de direitos humanos em diversos âmbitos e, mais recentemente, dos protestos de rua contra a Copa 2014. Embora haja um eixo comum que articula essa rede nacional, a mobilização coletiva e a elaboração de denúncias a partir dessa linguagem enfrentam a composição de força forjada em cada cidade-sede.

Passemos agora à análise do Comitê Popular da Copa de Porto Alegre, objeto específico de análise neste artigo.

\section{Comitê Popular da Copa e as Intervenções Urbanas em Porto}

\section{Alegre}

A constituição da rede política, em torno do CPC/POA, se formou em meados de 2010, quando representantes de distintas organizações e movimentos sociais (Movimento Sem Terra, (MST), Levante Popular da Juventude (LPJ),

\footnotetext{
${ }^{9}$ Ressalta-se aqui que em junho de 2013 as ruas das cidades brasileiras deram lugar a um intenso embate público acerca das políticas públicas urbanas governamentais. Para mais informações ver: Silva (2014); Damo (2014); Muhale (2014).
} 
Ponto de Cultura Quilombo do Sopapo, (PCQS), ONG Cidade, ONG Amigos da Terra (NAT/BR) passaram a se articular com moradores (ameaçados de remoção) na constituição de espaços não estatais de luta coletiva por conta de projetos urbanos da Copa 2014 na cidade.

A origem dessa configuração de forças é fruto, em grande parte, de experiências recentes de lutas sociais na cidade. Neste sentido, a vitória do Movimento "O Morro é Nosso", na defesa do Morro Santa Teresa, constitui-se num momento emblemático. Iniciado em 2010, o movimento foi formado por um coletivo plural - reunindo sindicatos, organizações sociais diversas, indivíduos, grupos civis e lideranças comunitárias - em torno da contestação de um projeto de lei do executivo estadual, que implicava na alienação de um terreno público localizado no Morro Santa Tereza.

O envolvimento das múltiplas organizações visou confrontar a apropriação de áreas públicas por grupos específicos da sociedade, particularmente pelos agentes da denominada especulação imobiliária. O Morro Santa Teresa, localizado no início da zona sul da cidade, com vista para a Orla do Rio Guaíba, é considerado uma importante área de preservação ambiental e histórico-cultural e componente da paisagística da cidade e, ao mesmo tempo, é habitado por quatro mil famílias que não possuem a posse regular dos seus terrenos. Através de uma série de caminhadas, marchas e distribuição de cartazes pela cidade, criou-se uma forte mobilização social (GUTERRES, 2011) em torno do direito à cidade, que resultou na retirada, em junho de 2010, do projeto de lei.

A derrubada de um projeto de governo e a conquista do comprometimento dos agentes governamentais de regularizar as moradias das famílias no seu local de origem passou a ser visto como uma oportunidade de fomentar outras formas de luta política na cidade. A vitória é importante na medida em que se deu no mesmo período no qual os governos municipal e estadual assinaram a Matriz de Responsabilidade, pactuando as intervenções a serem realizadas na cidade a tempo do início dos jogos.

Dentre os projetos assumidos, as principais obras a serem realizadas referem-se ao eixo "entorno do estádio", referente à arena oficial dos jogos, e que abrange a região do Morro Santa Teresa. O poder público municipal anuncia como o projeto de maior relevância a duplicação da Avenida Tronco. A justificativa em torno da sua prioridade é dada pela oportunidade que a Copa 2014 proporcionará de realizar uma importante obra de mobilidade urbana da cidade, facilitando o acesso ao estádio nos dias dos jogos do mundial. 
No entanto, o projeto viário governamental prevê a duplicação da avenida numa extensão de cinco quilômetros. O longo traçado abarca três bairros da zona sul da cidade ${ }^{10}$ - Cristal, Santa Teresa e Medianeira -, atravessando áreas públicas e privadas habitadas por 1500 famílias de sete vilas diferentes ${ }^{11}$. Assim, para concretizar a obra, o poder público municipal necessita deslocar as famílias que ali habitam.

As famílias impactadas pela duplicação tiveram o primeiro contato com o projeto da política pública no dia 19 de julho de 2010, numa reunião entre comunidades e governo municipal. O projeto viário elaborado por técnicos da prefeitura e apresentado por representantes da Secretaria do Município de Porto Alegre chegou pronto, sem alternativas ao traçado e sem uma solução concreta às moradias:

Foi apresentado um mapa. Eles colocaram na parede e mostraram que não tinha espaço. Mas nós não íamos sair da região. [...] O habitacional nunca foi apresentado. [...] Era só uma bela figura para encher os olhos. [morador da Vila Cristal]

É a partir desse momento que alguns moradores passam a se mobilizar para desenvolverem estratégias de resistência às ameaças de remoção. O histórico de atuação das organizações em torno do "Morro é Nosso" aproxima diferentes grupos sociais e resulta na articulação com parte das lideranças comunitárias das vilas. Constituiu-se, assim, um espaço organizativo de resistência, o qual se consolida na "região Cristal". Adquire centralidade nesse processo o Ponto de Cultura Quilombo do Sopapo, centro comunitário localizado no bairro Cristal, onde ocorrem as reuniões semanais de mobilização coletiva, articulando organizações sociais e famílias que serão removidas. A Criação dessa nova forma de organização comunitária passa a se engajar particularmente na construção da permanência das famílias na região de origem.

\footnotetext{
${ }^{10}$ Essa região vem sendo, pelo menos nos últimos quinze anos, palco de processos de disputas públicas acerca da ocupação do solo urbano, sobretudo o bairro Cristal. O atual bairro caracteriza-se por vasta infraestrutura urbana, grandes prédios comerciais, residências luxuosas e pela proximidade da Orla do Rio Guaíba, e, ao mesmo tempo, por uma ampla mancha de irregularidade fundiária.

${ }^{11}$ Vila Cristal, Vila Divisa, Vila Tronco, Vila Cruzeiro, Vila Maria, Vila Silva Paez, Vila Gaston Mazeron
} 
As ações da prefeitura frente à política de remoção estão atreladas ao cronograma do evento. A necessidade de finalizar a obra a tempo dos jogos resultou na elaboração de uma política habitacional específica para as famílias por meio de alterações dos mecanismos legais da política urbana. Assim, as ações da prefeitura frente à política têm configurado um regime legal específico "para a Copa", inscrevendo um Estado de Exceção no ordenamento jurídico (AGAMBEM, 2004). Direitos e garantias constitucionais são suspensas temporariamente com o objetivo de acelerar os processos decisórios para a organização.

Ilustrativo disto é que o anúncio, feito pelo prefeito de Porto Alegre, de que as unidades habitacionais para as famílias seriam realizadas através do programa federal Minha Casa, Minha Vida (MCMV) ${ }^{12}$ foi seguido pela aprovação na Câmara de Vereadores de um projeto de Lei Complementar, elaborado pelo próprio executivo municipal. Essa lei decretou que os reassentamentos pelo programa MCMV em função das obras de infraestrutura associadas à Copa 2014 não precisavam ser realizados em áreas identificadas na própria região de origem, alterando assim uma das principais conquistas dos movimentos de moradia local (SIQUEIRA; LAHOURGE, 2011).

As propostas apresentadas para os moradores, na reunião citada, foram o bônus moradia e o reassentamento via aluguel social, dois instrumentos da política habitacional com caráter emergencial. O bônus moradia é um recurso ofertado para as famílias comprarem uma casa escriturada. $\mathrm{O}$ valor é definido pela prefeitura e só pode ser utilizado por meio da negociação entre o poder público municipal e o proprietário da casa a ser adquirida. Já o aluguel social é um recurso assistencial mensal fornecido pela prefeitura às pessoas que se encontram sem local para morar. Ele foi proposto como alternativa para as famílias que desejassem optar pelo reassentamento em unidades habitacionais construídas pela prefeitura, na medida em que o cronograma governamental para a Copa 2014 previa o início da obra viária antes de as casas estarem prontas. No entanto, nenhuma informação adicional - sobre valores, prazos, destinos ou critérios - e nem garantias foram fornecidas aos moradores.

Em contraposição ao discurso da impossibilidade da permanência nas proximidades da região de origem, representantes das organizações e dos

12 Mais informações disponíveis em: http://wwwl.caixa.gov.br/gov/gov_social/municipal/ programas_habitacao/pmcmv. Acesso em 22 de abril de 2014. 
moradores se articulam, a partir do espaço do CPC/POA, e apresentam ao poder público municipal, em setembro de 2010, treze terrenos vazios, no bairro Cristal, como passíveis de desapropriação para a construção de moradias de interesse social ${ }^{13}$. O grupo passa também a buscar informações concretas e a possibilidade de incidir sobre a política pública governamental, garantindo a participação das famílias no processo decisório. Mas as tentativas frustradas de estabelecer um diálogo com a prefeitura levam moradores e organizações a constituir estratégias de denúncia da não observância dos direitos básicos das famílias.

É nessa conjuntura, que coloca em tensão o tempo para realizar uma avenida e o destino de milhares de famílias, que o CPC/POA passa a atuar e a se constituir como mediador entre famílias ${ }^{14}$ e agências governamentais. A partir da realidade vivida pelas famílias, a rede tem problematizado publicamente a ordem de prioridades envolvidas no projeto urbano governamental. Contrapõem-se as ações governamentais em prol da avenida a partir da afirmativa de que estas possuem direitos consolidados. Acionando o campo jurídico, inicia-se a elaboração de uma denúncia pública das remoções forçadas.

Todavia, a tentativa de constituir um espaço de enunciação pública acerca das remoções por meio da linguagem dos direitos humanos não é a garantia do seu exercício de fato, necessitando um intenso trabalho de construção, que envolve dimensões políticas e morais, se dando na interação entre organizações e indivíduos engajados no CPC/POA e outros agentes sociais e políticos. Conforme Zemans (1993), o direito constitui uma forma de poder contingente que só se efetiva na medida em que é mobilizado e, desse modo, a mobilização do direito é uma atividade política pelo meio da qual a autoridade pública das normas é convertida pelos agentes coletivos.

\footnotetext{
${ }^{13}$ Os terrenos foram desapropriados e gravados como áreas de interesse social em junho de 2013, no entanto, até o momento nenhuma moradia foi construída. Mais informações disponíveis em: www.camarapoa.rs.goc.br . Acesso em junho de 2014]

${ }^{14}$ Gostaria de ressaltar que o CPC/POA não possui essa relação com todas as famílias que estão passando pela política de remoção, existindo diversos conflitos entre as comunidades, os quais não poderão ser tratados aqui pelas limitações do artigo.
} 


\section{A Elaboração da Denúncia Pública e a Linguagem dos Direitos Humanos}

A situação problemática descrita dá início a uma disputa em torno dos significados e da legitimidade das intervenções governamentais e dos métodos para executá-las. Dessa maneira, as organizações e moradores participantes do CPC/POA passam a se engajar em ações que buscam transformar o caso das famílias ameaçadas de remoção num registro público a partir da elaboração de uma denúncia pública (BOLTANSKI, 2000). Conforme Araujo (2009), a fase da elaboração da denúncia pública é um importante momento na produção de um acontecimento político. Nesse sentido, um caso, que era em sua origem um problema local, visa ser transformado numa causa que diz respeito a todo mundo.

A denúncia elaborada a partir das ações do CPC / POA tem como núcleo central a noção de remoções forçadas, caracterizadas pela intervenção vertical do poder público, que não conta com a participação das comunidades nas decisões ${ }^{15}$. Desse modo, visa-se contrapor ao poder de intervenção do governo municipal de regulamentar os territórios urbanos, incidindo de maneira autoritária sobre as condições de vida e os destinos das famílias, recorrendo a uma consciência coletiva de que essa situação é inaceitável. No entanto, ao envolver-se com a construção da denúncia pública das remoções forçadas, o CPC/POA enfrenta o desafio de convencer as autoridades públicas e a população em geral de que a situação representa de fato uma injustiça, convencendo-as a associar-se ao seu protesto e mobilizá-las (BOLTANSKI, 2000).

$\mathrm{O}$ argumento em torno da noção de remoções forçadas mobiliza diversos mecanismos jurídicos (em nível local, nacional e internacional) que garantem o direito à cidade e à moradia das famílias (os quais asseguram a participação democrática das famílias): Constituição Federal, Estatuto da Cidade, lei orgânica do Município e pactos internacionais de direitos humanos, do qual o Brasil é signatário. Desse modo, a situação das famílias é traduzida para a linguagem jurídica, transformando-se numa causa dos direitos humanos.

A possibilidade de disputar publicamente a situação com o poder público se ampara na própria noção de universalidade contida no conceito de direitos humanos. Se as autoridades justificam suas ações em torno da

\footnotetext{
${ }^{15}$ Retirada de documento elaborado pelo CPC/POA á Presidência da República.
} 
política urbana a partir de uma retórica carregada pela ideia de oportunidade de desenvolvimento para toda a população porto alegrense, a denúncia do CPC/POA remete ao fato de que as famílias fazem parte desse todo e possuem direitos que têm que ser considerados. A chegada de uma obra de melhoria de infraestrutura urbana tem que beneficiar também os moradores atingidos pelo empreendimento.

Nesse sentido, reelabora-se a problemática da moradia no âmbito de elaboração da política pública em curso: ela não é uma questão técnica, mas um direito fundamental assegurado nos diversos mecanismos constitucionais. As famílias têm direito a uma moradia digna, ou seja, a moradia seria muito mais do que uma casa com quatro paredes, ela seria a possibilidade de acesso aos meios de vida, à água, a toda infraestrutura, à educação, à saúde (ROLNICK, 2012).

Assim, moradia e avenida são articuladas na noção de direitos: o direito à mobilidade urbana e a mobilidade das famílias como violação de direitos, envolvendo uma disputa de prioridades. "Para que esta avenida então senhor prefeito? Ela é tão importante assim? E nós para onde vamos? Nós temos direito, senhor prefeito" ${ }^{\prime 6}$. Aqui um componente importante da denúncia pública é a noção de comunidades consolidadas. As remoções forçadas incidem sobre famílias que habitam os terrenos há mais de quatro décadas e que constituíram nesse período importantes relações com e no território a ser modificado. A denúncia mobiliza como argumento as histórias das famílias com o seu local de moradia, ressaltando os laços familiares, de vizinhança e de amizade. Ela remete também a trajetória da luta comunitária a partir da qual conquistaram diversos dos equipamentos públicos existentes hoje nos bairros, que constituem atualmente uma região de alto valor cultural e imobiliário.

A utilização dos direitos humanos como linguagem de interação política tem como especificidade o fato de a denúncia envolver uma situação que diz respeito a uma violação de que o Estado é responsável (TISCORNIA, 2005; MACIEL, 2011). Desse modo, as remoções forçadas em função da construção de uma avenida têm como intuito provocar a ação responsiva das autoridades públicas frente às intervenções arbitrárias da prefeitura de Porto Alegre na dinâmica sociourbana da cidade.

\footnotetext{
${ }^{16}$ Questionamento de uma moradora da Vila Cristal ao prefeito de Porto Alegre.
} 
$\mathrm{O}$ enquadramento jurídico da denúncia pública a partir do CPC/POA coloca os representantes das organizações e moradores em interação com diferentes níveis do poder estatal local (executivo, legislativo, judicial e administrativo) e internacional (tribunais internacionais de direitos humanos), os quais circunscrevem a arena da denúncia de violação de direitos humanos. As estratégias em atuar em um e/ou outro nível é contingente, condicionado às possibilidades contextuais de ação, estratégias e relações de poder (MACIEL, 2011; TISCORNIA, 2005; BORGES, 2008 ).

As ações coletivas a partir do CPC/POA atravessam todos os níveis local, nacional e internacional. Através de campanhas, mobilizações de rua, audiências públicas com o ministério público estadual, denúncias no âmbito internacional e à Presidência da República e de uma articulação de visita de agentes da Organização das Nações Unidas (ONU) e do Grupo de Trabalho sobre Moradia da Secretaria de Direitos Humanos da Presidência da República para a verificação da violação de direitos humanos, o CPC/ POA vai compondo um repertório de ações coletivas de denúncia visando legitimar o processo de remoção no espaço público.

Esse percurso vai sendo trilhado ao longo da interação política conflituosa. A construção da denúncia tem início, no final de 2010, com a elaboração de documentos ao Ministério Público Federal e à prefeitura na tentativa de que as famílias possam ser protagonistas no processo de decisão sobre os seus destinos. Essas ações resultaram num ciclo de audiências públicas com diversas esferas governamentais - jurídica, legislativa e executiva. Com a falta de retorno efetivo por parte das diferentes instâncias públicas, as organizações sociais passam a elaborar denúncias no âmbito internacional (Conselho de Direitos Humanos da Organização das Nações Unidas - ONU) com o intuito de sensibilizar os representantes da ONU para que profiram recomendações aos governos brasileiros para suspender as remoções forçadas.

A primeira ação em torno dos direitos humanos de que eu participei junto ao CPC/POA, com referência em nível internacional, foi a vinda da relatora do direito à moradia digna da ONU, Raquel Rolnik ${ }^{17}$. A visita de Rolnik a Porto Alegre se deu a partir das relações com a rede nacional dos Comitês e visava como resultado à produção de um documento relatando as violações

\footnotetext{
${ }^{17} \mathrm{~A}$ intervenção dela se vincula ao trabalho desenvolvido junto à relatoria da ONU sobre megaeventos dos mais diversos tipos e ao impacto destes nos países.
} 
de direitos na cidade. Relato sinteticamente a visita por ser ilustrativa dos esforços do CPC/POA de tornar o caso das famílias uma causa coletiva.

Raquel Rolnik chegou a Porto Alegre no dia 18 de agosto de 2011. Em sua agenda, as visitas às comunidades em situação de remoção eram a principal atividade. O trajeto que ela percorreu, elaborado por representantes do CPC/ POA e de outros apoiadores da luta urbana em Porto Alegre, resultou na visita de diferentes vilas na cidade ${ }^{18}$ localizadas em regiões que estão passando por grandes intervenções urbanas que têm colocado milhares de famílias em situação de ameaça. Assim, a situação das famílias atingidas pela duplicação da Avenida Tronco vai sendo costurada a outras histórias semelhantes da cidade, visando-se estrategicamente tornar o problema particular de uma avenida em um caso exemplar. Ao se desenhar um quadro das remoções forçadas na cidade, buscava-se também identificar o prefeito como o sujeito responsável pelas violações, explicitando, assim, que as políticas urbanas por parte do poder público municipal caracterizavam-se por projetos urbanos que implicam violações de direitos humanos. Desse modo, a visita teve como objetivo visibilizar as remoções como problema coletivo e público e provar as injustiças causadas pela prefeitura.

No processo de elaboração da denúncia pública, o CPC/POA passa a se envolver numa intensa disputa argumentativa com os seus "adversários", os quais levantam argumentos para buscar fazer com que seus interesses sejam reconhecidos como justos (ARAUJO, 2009). Em grande medida, a mídia e o próprio poder público têm se utilizado estrategicamente da palavra "invasores" para descaracterizar essas famílias e deslegitimar as mobilizações coletivas de permanência na região. Um exemplo em que o sujeito de direitos e o estigmatizado se encontram foi uma situação que presenciei em campo, quando estávamos reunidos no espaço do Quilombo do Sopapo, numa reunião do CPC/POA, e um representante de uma das organizações colocou um áudio para ouvirmos, no qual o prefeito de Porto Alegre dava uma entrevista à rádio sobre as obras da Copa 2014, e, num determinado momento, ele argumentou, referindo-se ao CPC/POA, que havia "pessoas baderneiras contra o progresso da cidade”. O áudio provocou agitação entre as lideranças presentes, que imediatamente afirmaram que queriam direito

\footnotetext{
${ }^{18}$ Raquel visitou, além das vilas atingidas pela duplicação da Avenida Tronco, as vilas do Morro Santa Teresa, a Vila Dique, a Vila Chocolatão e a Ocupação 20 de Novembro. Mais informações disponíveis em: www.comitepopularcopapoa2014.blogspot.com.br. Acesso em: junho de 2014.
} 
de resposta, pois afirmavam elas: não somos contra o progresso, só queremos os nossos direitos. A situação ilustra um importante papel simbólico do direito para as famílias no enfrentamento com os estigmas de marginalidade. Dessa maneira, o uso da linguagem de direitos humanos visa simbolicamente dar credibilidade e reconhecimento a essas famílias, de modo que pretende inverter a acusação de que eles seriam invasores para torná-los sujeitos desprovidos de um direito humano básico: o direito à moradia.

Mesmo com todos os esforços em torno da denúncia pública das remoções forçadas, as obras da avenida iniciaram em maio de 2012 num dos trechos da via projetada que não necessitava de remoções. Tendo em vista a necessidade de avançar com as obras, o poder público local, a partir do Departamento Municipal de Habitação (DEMHAB), instalou o Escritório Nova Tronco, numa das Vilas atingidas pelas obras, para tratar da retirada das famílias. As modalidades ofertadas naquele momento eram o bônus moradia, definido agora no valor de 52 mil reais, o reassentamento via aluguel social - no valor de 400 reais mensais - e a indenização para casos em que a moradia possuísse um valor maior. Nessa nova fase de implementação da política urbana, outros elementos passam a figurar na denúncia pública: a ação da prefeitura via escritório, o início da derrubada das casas e os instrumentos utilizados como política pública.

Nessa conjuntura é lançada a Campanha Chave por Chave, a qual se refere ao fato de que os moradores só deixariam suas casas quando tivessem a chave da casa nova. A campanha, a qual foi definida em assembleia entre representantes do CPC/POA e moradores, é um repúdio ao aluguel social como possibilidade de política pública. Este é referenciado como cheque despejo, pois seria uma maneira de retirar as famílias para que as obras pudessem se concretizar, mas elas continuariam na situação de vulnerabilidade e à mercê das decisões estatais. A oposição ao bônus moradia se referia ao valor muito abaixo da realidade da cidade, que estaria levando a uma migração forçada das famílias para bairros distantes e até mesmo para cidades vizinhas (como foi o caso de Dona Joana, relatado no início do artigo), resultando na fragmentação comunitária.

A saída de algumas famílias das vilas deu início a um cenário de constrangimentos e violência. Ao optarem pelas políticas (bônus moradia, aluguel social ou indenização), assinavam um documento que autorizava os funcionários da prefeitura à demolição imediata das casas; no entanto, os entulhos não eram recolhidos, proliferando-se lixos e ratos na vila. Nas reuniões do $\mathrm{CPC} / \mathrm{POA}$ com os moradores, os relatos faziam referências às 
coações sofridas no Escritório violador de direitos humanos.

Naquele momento, as principais estratégias em torno da denúncia pública eram as possibilidades de filmar e publicizar as situações de violação sofridas pelas famílias, em particular para o governo federal, demonstrando a ele que estava financiando violação de direitos humanos. A ação descrita no início deste artigo (a tentativa de filmar a remoção de Dona Joana) era parte desse repertório de denúncia de violações de direitos humanos.

\subsection{Direitos humanos como uma linguagem especializada}

A busca por direitos exige que as pessoas se envolvam em políticas específicas e processos jurídicos (COWAN; DEMBOUR; WILSON, 2001). Ao acionarem a linguagem dos direitos humanos como recurso para denúncia pública, organizações e moradores se envolvem num campo político imbricado em relações de poder delimitado pelo conhecimento de um saber específico. Desse modo, para acionar a linguagem dos direitos humanos como um campo possível de luta, é preciso ter conhecimentos técnicos, saber manejar a linguagem burocrática, falar a língua dos universais, saber quem articular. Nesse sentido, a literatura tem apontado a importância da presença de mediadores nas lutas por direitos (MACIEL, 2011; BORGES, 2009; TISCORNIA, 2005).

A possibilidade do CPC/POA em atuar a partir dessa linguagem como um recurso para sustentação do processo conflituoso resulta do fato de os representantes das organizações terem como característica serem "técnicos" na questão em que estão envolvidos. Estes em sua maioria transitam por diferentes espaços - o acadêmico e os espaços institucionais da política - e acabam constituindo um conjunto de saberes especializados, que é levado para a sua atuação no CPC/POA. Os representantes são também profissionais das áreas de arquitetura, geografia e direito, as quais são reconvertidas em militância e, ao mesmo tempo, possuem trajetória em organizações sociais que os colocam em contato direito com a linguagem das políticas públicas, particularmente em torno da habitação e do funcionamento do Estado. Tal fato possibilita uma "politização da técnica", isto é, o uso de saberes especializado como recurso de luta política.

Mas o manejo da linguagem dos direitos humanos depende não apenas um saber de como acioná-los, mas a quem acionar e como tornar legítima a denúncia de violação (um exemplo desse tipo 
de estratégia foi a articulação para a vinda da relatora da ONU de direitos humanos, conforme descrito anteriormente). Nas diversas estratégias de ações a partir da linguagem de direitos realizadas pelo CPC/POA (descritas anteriormente), os representantes das organizações precisavam mobilizar diversos agentes influentes e especializados, organizar seminários bem como as comunidades para as visitas de órgãos públicos, além de fazer o levantamento de informações, tal como a construção de relatórios sobre as violações de direitos humanos, oficinas e mutirões com a intenção de explicar às comunidades atingidas pelas remoções da Copa 2014 os direitos que possuíam. Eu me formei na luta, aprendi muito. Nós fomos arquitetas, engenheiras, sabemos tudo de direito. Eu fui diplomada em direitos. A gente agradece pela comunidade ter sido abraçada por vocês. Vocês trouxeram o conhecimento (relato de uma moradora do Morro Santa Teresa numa reunião do CPC/ POA)

Para além do conhecimento acerca da linguagem dos direitos humanos, sempre foi afirmado pelo CPC/POA a necessidade de mobilizações coletivas para que as denúncias pudessem ser efetivas e legítimas. Exemplo foi a presença de dois advogados, levados pela representante do MST, na reunião do CPC/POA, para discutir uma ação jurídica possível para desapropriar terrenos na região das comunidades. A função dos advogados era tornar acessível a linguagem jurídica para o entendimento das comunidades, mas, junto com a ação judicial, ressaltavam que era necessária a mobilização:

Vocês sabem que quem decide é o judiciário e que a chance de resultado é pequena, não se pode contar com isso. A ação é interessante na medida que dá visibilidade ao nosso argumento, mas é secundária. É preciso povo na rua. (advogado vinculado ao MST)

As experiências junto ao CPC/POA explicitam que apenas mobilizar o direto a partir de ações judiciais ou de denúncias públicas não é suficiente, sendo necessário um reconhecimento político e social de que as remoções forçadas constituem violações de direitos humanos merecedoras de "reparação". Essa afirmação vai ao encontro da afirmativa de que os direitos humanos são produções históricas e culturais e resultam de tensas lutas políticas e dinâmicas específicas (SCHUSCH, 2009; FONSECA; CARDELLO, 2001; RIBEIRO, 2004). 


\subsection{Direitos Humanos como Ferramenta de Luta: apropriações e significados}

o povo não acredita, nós falamos que eles têm direito, mas eles não acreditam em nós...e sem o povo...o povo é o combustível. (morador da Vila Cristal e integrante do CPC/POA)

Essas palavras eu ouvi de seu Zé, uma das lideranças comunitária ativas no CPC/POA, em resposta a minha indagação sobre a ausência das famílias numa atividade de mutirões de direitos humanos organizada pelo CPC/ POA, em agosto de 2013, num espaço público nas proximidades das vilas que são alvo das intervenções do poder público municipal. Esse episódio é ilustrativo aqui de duas questões.

Por um lado, a fala de seu Zé remete ao fato de que uma denúncia pública, para ser efetiva, depende da participação da "vítima". No meu campo de pesquisa, conquanto o movimento tenha acionado a linguagem dos direitos humanos na interação conflituosa com a prefeitura, os efeitos em termos de mobilizar as famílias a partir dessa linguagem têm sido pequenos, o que dificulta que o CPC/POA tenha sucesso na disputa acerca dos rumos das políticas públicas urbanas.

Por outro, evidencia a existência de uma tensão entre o discurso dos direitos humanos e a percepção destes como alternativas para as demandas das famílias. Nesse ponto, eu gostaria de voltar a história com a qual eu iniciei este artigo (da Dona Joana). A resposta de Dona Joana ("acionou a mídia local para resolver o seu problema") a minha "oferta" de uma solução jurídica ("vocês não acionaram um advogado? Isto se constitui numa violação de direitos humanos!"), amparada em preceitos universais, revelava outra lógica, pessoalizada, que orientava suas ações na solução da problemática que envolvia a sua moradia. A mídia local aparece aqui como uma mediadora capaz de tornar eficaz o atendimento de sua demanda e chama a atenção para o fato de que, na verdade, o direito e suas instituições figuram como mais um dentre os vários recursos políticos e culturais por meio dos quais grupos ou indivíduos podem vocalizar suas insatisfações. $\mathrm{O}$ uso do direito ou dos tribunais é condicionado às interpretações dos sujeitos envolvidos acerca dos custos e oportunidades implicados (MACIEL, 2011).

Dessa situação desdobra-se a importância da dimensão da eficácia do recurso mobilizado na resolução da situação problemática no curso das disputas políticas. Voltando ao seu Zé, numa outra conversa que tivemos 
sobre a trajetória da luta em torno dos direitos humanos a partir do CPC/ POA:

eu não acredito em mais ninguém. No ministério público? Não acredito. Na prefeitura? Não acredito. Na ONU? Não acredito. Não acredito em nenhuma instituição! Depois de tantos documentos que elaboramos mostrando as violações de direitos e eles não fizeram nada. Se isso não é violação de direitos humanos, então, não acredito em ninguém.

O que essas situações parecem demonstrar não é uma passividade das famílias por não aderirem à luta por direitos, mas diferentes lógicas e ações empregadas por parte dos moradores como resposta num processo de resistência cotidiana frente ao cenário de extremo constrangimento por que estão passando. Ao mesmo tempo, para aqueles que se engajam na luta por direitos, é preciso percorrer um trajeto difícil e cansativo, deslocando-se do âmbito privado para o público e se inserindo no tempo da política. Para se constituírem como sujeitos políticos de direitos, precisam saber manejar conhecimentos específicos e esperar o tempo da burocracia, tendo muitas vezes como resultado das denúncias um maço de relatórios que "orientam ações ao Estado".

A fala de outra moradora, pronunciada numa reunião do CPC/POA, é ilustrativa da dificuldade de incentivar as pessoas para a luta em termos jurídicos na conjuntura vivenciada por conta dos efeitos da política pública urbana:

Está sendo construído um cenário de violência que é incentivado todos os dias, a comunidade está definhando. Esta semana mataram aqui na Vila dois adolescentes [...] está difícil de incentivar as pessoas. Elas já resistem cotidianamente há muito tempo

Outro elemento que parece dificultar a mobilização é a condição de irregularidade fundiária ("os estigmas") que marca as famílias, que impõem obstáculos acerca da legitimidade de se reivindicar publicamente direitos. Neste sentido, o lugar de onde falam (da vila, do despossuído, do ilegal) estabelece constantemente dificuldades para travar essa luta, envolvendo custos (materiais, e simbólicos) para as famílias ao se tornarem denunciantes de violações de direitos humanos. Afinal, é sobre elas (as famílias) que as denúncias falam. São elas que necessitam expor sua vida e seus sofrimentos publicamente a fim de serem avaliados em seu sentido de justiça por uma 
opinião externa. Um episódio que eu experienciei em campo expressa um pouco o enfrentamento constante do estigma da marginalidade: A reunião já tinha começado, quando um grupo de pessoas chegou ao local. [...] uma das mulheres que recém tinha chegado pediu para falar. Apresentou-se como conselheira do OP e moradora de uma das vilas que seria removida. Disse que estava muito preocupada, que tinha ido a uma reunião que foi feita às escondidas [...] Se soubéssemos antes, só a vila do R. tem muito mais gente que eles. "Eles" era referência à classe média do bairro. Sua preocupação era a apresentação de um abaixo-assinado com mais de 1.800 assinaturas contra a permanências das famílias. Falou que a reunião foi muito pesada e que falaram para o Baggio (Secretário de Gestão e Acompanhamento Estratégico) que, se ele gostava tanto de pobre, que levasse para a casa dele. Nós fomos apresentados como o lixo do Cristal.

Referindo-me novamente à história de dona Joana, ilustro outros riscos temidos pela reivindicação de direitos.

Naquele dia, depois de já termos iniciado as filmagens para elaborar a denúncia acerca das violações, o genro de dona Joana chegou ao local para ajudar na mudança. Ao nos ver, ele prontamente nos questionou sobre o que estávamos fazendo ali e, ao ficar sabendo da nossa intenção, nos disse: eu não quero que vocês utilizem estas filmagens, eu trabalho como mestre de obra na casa de três juízes e não quero me incomodar com isto.

Para finalizar, mas sem pretensões de esgotar este debate, atento para as profundas desigualdades brasileiras que remetem a uma situação de "não direito". Como me disse uma das moradoras quando saímos de uma reunião do CPC/POA: Na vila não temos direitos. Eles não existem. A policia chega aqui e bate em quem quiser. Fazem o que quiser aqui, se quiserem matar, matam. Desse modo, ela referia-se a casos em que há abolição de direitos constitucionais em algumas práticas governamentais em regiões de populações pobres, revelando uma realidade que desmente que o Estado opera pela lógica de acesso aos direitos constitucionais de forma igualitária a todos seus cidadãos.

\section{Considerações Finais}

As políticas públicas urbanas brasileiras vêm sendo articuladas a um novo momento político caracterizado pela atração do fenômeno dos megaeventos esportivos. Resultam desse processo grandes obras de infraestrutura urbanas, as quais têm implicado numa mudança significativa da dinâmica sociourbana nas cidades brasileiras, em especial o deslocamento de um 
grande contingente populacional que habita assentamentos irregulares. Essa conjuntura tem reconfigurado os conflitos urbanos contemporâneos no país, emergindo amplas redes políticas contestatórias amparadas na noção de direitos humanos. Atentando para as especificidades contextuais dessa nova conjuntura, este artigo buscou contribuir a analítica da interface entre direito e dinâmicas políticas contemporâneas.

Delimitando como objeto de investigação as mobilizações coletivas do CPC/POA na elaboração de uma denúncia pública das remoções forçadas frente às intervenções governamentais na elaboração de uma política pública associada à preparação da cidade para os jogos da Copa FIFA 2014, busquei compreender o modo como as organizações sociais e os moradores têm se utilizado da linguagem jurídica como recurso de interação política.

A análise amparada em pesquisa etnográfica buscou, num primeiro momento, demonstrar como a linguagem dos direitos humanos se configura num campo possível de ser acionado e apropriado pelas organizações sociais como recurso para sua luta, enfatizando as dimensões estratégicas e simbólicas da ação coletiva. Partindo disto, tentei explicitar, por meio do caso empírico, algumas implicações resultantes da apropriação desse campo específico: o que está em jogo no uso dos direitos humanos como uma retórica para ação, discutindo a construção da denúncia pública a partir de algumas dimensões envolvidas (moral, coletiva, política e generalizável); a interação com uma arena de denúncia específica que envolve diferentes níveis de poder (executivo, legislativo, judiciário e tribunais internacionais); a relação das mobilizações sociais com um campo que detém um saber específico, necessitando o manejo de uma determinada linguagem, e a importância dos mediadores; e os diferentes significados dos direitos humanos para movimentos sociais e famílias atingidas pelas políticas de remoções.

Por fim, expus sobre as diferentes percepções da apropriação da linguagem jurídica como forma de enquadrar e resolver situações sociais dos sujeitos envoltos no conflito com autoridades públicas, chamando a atenção para a complexidade das lutas coletivas em torno dos direitos humanos, em especial num país com longa trajetória de desigualdade social. Assim, se, por um lado, acionar os direitos humanos possibilita e legitima a ação em diferentes esferas institucionais, por outro, há riscos de descolamento em relação à população a ser mobilizada, que em grande medida não se identifica com essa linguagem ou não a percebe como meio eficaz de resolução de suas demandas, acionando outras instituições mediadoras. Propus a partir dos dados empíricos da minha pesquisa algumas reflexões sobre esta questão 
(a dimensão dos estigmas e a forma histórica estatal de lidar com esses grupos populacionais, por exemplo), no entanto, tais evidências empíricas necessitam ser mais bem trabalhadas em trabalhos futuros.

\section{Referências}

AGAMBEN, Giorgio.

(2004). Estado de Exceção. Trad. Iraci di Poleti. 2. Ed. São Paulo: Boitempo.

ÁLVARES, Lúcia, BESSA, Altamiro, BARBOSA, Thiago.

(2013). Empresariamento da cidade e geração de conflitos: as várias faces da Copa 2014 em Belo Horizonte. Anais da Associação Nacional de Pós-graduação em Planejamento Urbano e Regional (ANPUR), vol. 15.

ARAUJ0, Fábio.

(2008). Falta alguém na minha casa: desaparecimento, luto, maternidade e política. In: Roberto Kant de Lima. (Org.); Antropologia e Direitos Humanos V. Brasília, Booklink.

BOLTANSKI, Luc.

(2000). El amor y la justicia como competências: três ensayos de sociologia de la acción. Buenos Aires, Amorrotu.

BORGES, Nadine.

(2008). 0 caso de Damião Ximenes: uma análise sócio-jurídica do acesso à comissão e a corte interamericana de direitos humanos. Dissertação de Mestrado apresentada ao Programa de Pós-Graduação em Sociologia e Direito da Universidade Federal Fluminense.

CAFRUNE, Marcelo.

(2010). Mediação de Conflitos Fundiários Urbanos: do Debate Teórico à Construção Política. Revista da Faculdade de Direito UniRitter, n. 11.

CARDOSO DE OLIVEIRA, Luís Roberto.

(2010). A dimensão simbólica dos direitos e a análise de conflitos. Revista de Antropologia, Vol. 53, no 2, p. 451-473.
COWAN, Jane; DEMBOUR, Marir-Benedicte; WILSON, Richard Ashby (Eds.).

(2001). Introduction. In: Jane Cowan; MarirBenedicte Dembour; Richard Ashby Wilson (Eds.); Culture and Rights. Anthropological Perspectives. Cambridge: Cambridge University Press. p. 1-26.

DAM0, Arlei.

(2014). A Copa das Manifestações. In: Antônio Davi Cattani (Org.); \#Protestos: análises das Ciências Sociais. Porto Alegre: Tomo Editorial.

Dossiê da Articulação Nacional dos Comitê Populares da Copa. 2. Ed.

(2014). Megaeventos e Violações de direitos Humanos no Brasil. Disponivel em: http://www.apublica.org/wp-content/ uploads/2012/01/DossieViolacoesCopa.pdf . Acesso em dezembro de 2014.

FONSECA, Cláudia. CARDARELLO, Andrea. (1999). Direitos dos mais e menos humanos. Horizontes Antropológicos, vol. 10, p.83-122.

FREIRE, Letícia.

(2013). Mobilizações Coletivas em contexto dos megaeventos esportivos no Rio de Janeiro. 0 Social em questão, ano XVI, nº 29.

GARCIA, Fernanda; LIMA JUNIOR, Pedro; HERDY, Fabrícia.

(2011). A estratégia urbano territorial do ProjetoOlimpico Rio 2016: notas sobre as propostas para mobilidade e transportes. Disponível em: http://observatoriogeograficoamericalatina. org.mx/egal13/Geografiasocioeconomica/ Ordenamientoterritorial/55.pdf . Acesso em dezembro de 2014. 
GUTTERRES, Anelise.

(2011). Os jogos sociais nas cidades dos megaeventos esportivos: etnografia em redes e sociabilidades políticas efervescentes, no contexto de Porto Alegre - RS. Iluminuras, v. 12, n.27. Disponivel em: http://seer.ufrgs.br/ iluminuras/article/view/21188/pdf. Acesso em outubro de 2011.

MACIEL, Débora.

(2011). Ação Coletiva, Mobilização dos Direitos e Instituições Políticas: o caso da Campanha da Lei Maria da Penha. Revista Brasileira de Ciências Sociais, vol.26, n. 77, p. 97-11.

MAGALHÃES, Alexandre.

(2013).0 “legado" dos megaeventos esportivos: a reatualização da remoção de favelas no Rio de Janeiro. Horizonte Antropológicos, vol. 19, no 40.

MARGARITES, Gustavo.

(2014). Políticas Urbanas em Contextos de megaeventos esportivos: a formulação da política habitacional para a duplicação da Avenida Tronco em Porto Alegre. Dissertação apresentada ao Programa de Pós-Graduação em Sociologia da Universidade Federal do Rio Grande do Sul.

MASCARENHAS, Gilmar; BORGES, Fátima.

(2009). Entre o empreendedorismo urbano e a gestão democrática da cidade: dilemas e impactos do Pan-2007 na Marina da Glória. Esporte e Sociedade, ano 4, n.10.

MUHALE, Miguel.

(2014). Lutar, criar, poder popular: uma perspectiva etnográfica do Bloco de Lutas pelo Transporte Público em Porto Alegre/ RS. Dissertação apresentada ao Programa de Pós-Graduação em Antropologia Social da Universidade Federal do Rio Grande do Sul.

RAEDER, S.

(2009). Conflitos no ordenamento territorial em sedes de megaeventos esportivos. Esporte e Sociedade, ano 4, n.10.

RIBEIR0, Gustavo Lins.

(2004). Cultura, direitos humanos e poder. Mais além do império e dos humanos direitos. Por um universalismo heteroglóssico. In: Claudia
Fonseca; Veriano Terto Jr; Caleb Faria Alves et al; (Orgs.); Antropologia, diversidade e direitos humanos: Diálogos interdisciplinares. Porto Alegre: Editora da UFRGS.

SILVA, Marcelo Kunrath.

(2014). \#vemprarua: o ciclo de protestos de 2013 como expressão de um novo padrão de mobilização contestatória?. In: Antônio Davi Cattani (Org.); \#Protestos: análises das Ciências Sociais. Porto Alegre: Tomo Editorial.

SIQUEIRA, Lucimar.

(2011). A duplicação da Av. Tronco e a política habitacional de Porto Alegre, disponível no site http://reformaurbanars.blogspot.com. br/2011/02/duplicacao-da-av-tronco-epolitica.html. Acesso em dezembro de 2014.

SCHUCH, Patrice.

(2009). Entre o “real" e o "ideal": a Antropologia e a construção de enunciados sobre "direitos humanos". In: Patrice Schuch; Práticas de justiça. Antropologia dos modos de governo da infância e juventude no contexto pós-ECA. Porto Alegre, UFRGS.

TISCORNIA, Sofia.

(2005). Límites al poder de policía. Ela activismo del derecho internacional de los derechos humanos y el caso Walter Bulacio ante la Corte Interamericana de Derechos Humanos. In: Sofia Tiscorinia; Maria Victoria Pita (Orgs.); Derechos humanos, tribunales y policias en Argentina y Brasil: Estudios de Antropología Jurídica. Buenos Aires: E.A.

ZEMANS, Frances.

(1983). Legal Mobilization: The negleted role of the Law in the Political System. The American Political Science Review, Vol. 77, nº 3.

\section{Recebido em}

fevereiro de 2014

\section{Aprovado em}

agosto de 2014 